\title{
Effective environmental management through environmental knowledge management
}

\author{
$1{ }^{*}$ Po-Shin Huang; ${ }^{2}$ Li-Hsing Shih \\ ${ }^{1}$ Meiho Institute of Technology, Pingtung and Department of Resource Engineering, National Cheng Kung University, \\ Tainan, Taiwan \\ ${ }^{2}$ Department of Resource Engineering, National Cheng Kung University, Tainan, Taiwan
}

Received 22 July 2008; $\quad$ revised 16 September 2008; accepted 26 November 2008; $\quad$ availavble online 10 December 2008

\begin{abstract}
Owing to the green revolution, environmental problems have now become some of the most important issues worldwide. Environmental knowledge management, which combines the strengths of environmental management and knowledge management, will become a popular tool for businesses in the near future. In this paper, through interviews of staff at different levels and in different departments of the business, i. e. managers and engineers and using the environmental knowledge circulation process, the authors evaluate the success of environmental knowledge management when applied to China Steel Corporation in Taiwan. From the case study, the authors found that China Steel Corporation has applied the environmental knowledge circulation process for over thirty years. The company continually improves its environmental and financial performance through environmental knowledge creation, environmental knowledge accumulation, environmental knowledge sharing, environmental knowledge utilization and environmental knowledge internalization. Water pollution and air emissions have reduced year on year and total energy consumption has reduced by $20 \%$ from 1979 to 2006. On the other hand, China Steel Corporation also makes a profit and reduces cost through energy sold, by-products and recycling. Continuous improvement in environmental knowledge management has rendered China Steel Corporation in the most profitable steel company in Taiwan and the world's twenty fifth largest steel producing company in 2006.
\end{abstract}

Key words: Environmental knowledge circulation process, environmental performance, tacit knowledge, explicitl knowledge

\section{INTRODUCTION}

Through globalization and the Earth's natural processes, local environmental problems have transformed into international pollution issues. In order to solve these pollution problems, environmental management (EM) and green supply chain management (GSCM) have been widely adopted by enterprises with the aim of reducing pollution and evaluating environmental performance (Boiral, 2002; Chien and Shih, 2007; Hsu and Hu, 2008). Environmental protection and performance have become two of the world's most important priorities in order to attain sustainable development (Nouri et al., 2008)

Over the previous decade, EM has moved away from a regulatory-based approach to one focusing on continuous development. Knowledge management (KM) has also rapidly developed over the last decade. A review of the literature shows that KM was first

ه*Corresponding Author Email: kevinhuang3145@yahoo.com.tw Tel.: +8868 735 1312; Fax: 88687351318 introduced in theoretical research and has since been developed for application in the identification and solving of a variety of problems. Environmental knowledge management (EKM) is also defined as a system to connect data, analysis and people which presents an opportunity to formalize industrial ecology in a business setting (Wernick, 2003). It is also clear from the literature review that KM and EM have both been studied for many years; however, the key aspect of successful EM is effective KM which provides employees at all levels of an organization with a computerized and systemized EKM system enabling staff to gain environmental awareness and make environmentally responsible business decisions.

The objective of this study is to identify the extent and scope of EKM used in the case study and evaluate its performance from the viewpoint of the knowledge circulation process (KCP) (Lee et al., 2005). This paper begins with a discussion of knowledge management 
and environmental management and then outlines environmental knowledge management using the environmental knowledge circulation process (EKCP). The case study in which environmental knowledge management principles are applied and the business responsibility for the sustainable development of the enterprise is derived may lead to the improvement of environmental and financial performance.

This study has been surveyed between May 2007 and February 2008.

\section{Environmental management and knowledge management \\ Environmental management \\ Petak (1980) defined EM as managing human affairs} so as to achieve acceptable balance between the quality of the human environment and the quality of the natural environment. At that time, EM was still being used to find a balance between the environment, ecology protection and economics. According to Lorrain-Smith (1982), the element of "control” should be added to environmental management; hence, he redefined environmental management as an action taken by society, a section of society and an organization to improve environmental quality by developing plans, implementing them and continuously reviewing them introducing the concept of control after the pollution problems have been caused. Traditional end of pipe pollution control mechanisms were widely adopted in this period; however, they are neither technologically efficient nor cost effective and may cause serious environmental impacts (Mangun, 2001).

The US Environmental Protection Agency (US EPA) and the Pollution Prevention Act (Bishop, 2000) define pollution prevention as source reduction, material substitution and more efficient processes in order to prevent all kinds of pollutants from the very beginning of the manufacturing process. In 1995, environmental management was used to enhance environmental sustainability development (Goodland, 1995). The three requirements of economic growth, social justness and sustainability in the use of natural resources should be kept in balance (Dourojeanni, 1993). As indicated above, it is clear that great progress has been made in EM in recent years developing from passive pollutant control to the initiation of prevention right from the start of the process and moving forward to encompass the concept of environmental sustainable development.

\section{Knowledge management}

In today's fast changing environment, knowledge is the highest source of power (Toffler, 1990) and how a company creates and shares its knowledge is the main source of sustainable competitive advantage and profitability (Prahalad and Hamel, 1990; Nonaka, 1991; Hansen et al., 1999; Desouza and Evaristo, 2003). Hence, knowledge is a very important and powerful resource for organizations to use it in the preservation of heritage, accumulation of experience, creation of new ideas and sharing of new knowledge.

In the knowledge-based economy, KM has replaced the traditional factors of production, including land (i. e., natural resources), labor and capital (Drucker, 1995) and has become a key factor in the success of a business. According to Malhotra (1998), KM is defined as containing organizational processes that seeks a synergistic combination of data and the informationprocessing capacity of information technologies and the creative and innovative capacity of human beings. Quinn et al. (1996) defined KM generally as including any processes and practices that are concerned with the creation, acquisition, capture, sharing and use of knowledge, skills and expertise. The key purpose of an enterprise knowledge management is to make information and knowledge accessible, reusable and sharable (O'Leary, 1998) and concerns the harnessing of the intellectual assets of an organization in order to improve its learning capability (Swan et al., 2000).

In general, $\mathrm{KM}$ is the collection, integration and classification of disordered information, technology and expertise in an enterprise and provides systematic and organized information for internal employees or management-level staff to consult when undertaking new tasks and decision-making.

$\mathrm{KM}$ is a kind of enterprise asset that can help an organization to create new technology and achieve specific outcomes such as shared intelligence, improved performance or competitive advantage.

The question of how to gain control of knowledge assets has become a major organizational concern (Hansen et al., 1999; Swan et al., 2000). Knowledge and expertise have been viewed as the most strategic and efficient inputs for an enterprise in the quest to achieve a sustainable competitive advantage (Johannessen and Olsen, 2003). KM represents a new science and technology that provides competitive conditions and advantages for the modern business (Sarvary, 1999). 
Moreover, Sarvary (1999) also stated that with a good KM system, the job is much more challenging and people can concentrate on problem solving rather than on number crunching and data collection. Effective knowledge management has a great impact throughout the enterprises from the lower levels of manufacturing to the management levels of strategic decision-making. Hence, through the efficient management of knowledge, an enterprise can create new technology and a unique business strategy that will improve its performance and competitive advantage.

\section{Environmental knowledge management}

Environmental knowledge and environmental knowledge management

The ideas of the sustainable development as introduced in the Brundant report (WCED, 1987) have being become increasingly important. Achieving sustainable development to combine environmental management and knowledge management is an indispensable ingredient. Wagner (2005) found that for firms with pollution prevention-oriented corporate environmental strategies, the relationship between environmental and economic performance is more positive thus making improvements in corporate sustainability are more likely. However, it is a quite new issue pertaining to how to combine KM with EM and apply them into real situation. Nonaka et al. (1996) defined tacit knowledge as a kind of personal characteristic that is too abstract to transfer or even express using words. Howells (1996) thought that tacit knowledge is a kind of expertise that is not editable. This knowledge is obtained through informal learning behavior and a sequence process.

Therefore, environmental knowledge management must combine the management of explicit knowledge and tacit knowledge management in an organization and control the environmental impact via the accumulation, utilization, sharing and creation of environmental knowledge.

Environmental knowledge is a kind of general knowledge and includes the concepts of environmental protection, the natural environment and ecosystems (Fryxel and Lo, 2003).

This means that environmental knowledge involves what people know and are concerned about regarding to the natural environment, their responsibilities towards environmental protection and the relationship between the economy and sustainable development.
People with environmental knowledge will process information using this knowledge (system knowledge), know what can be done about the environmental problems (action related knowledge) and understand the benefits (effectiveness) of environmentally responsible actions (Frick et al., 2004).

A current business trend is towards the use of KM and EM and governments and organizations are concentrating on these concepts. The concept of EKM combines the management of explicit knowledge and tacit knowledge in an organization and controls the environmental impact via the accumulation, utilization, sharing and creation of environmental knowledge; it is essentially a fusion of knowledge management and environmental management. EKM also integrates environmental problems into an organization's routine operations in order to reduce environmental pollution and increase business responsibility and concern towards the natural environment.

Tatsuki and Masahisa (2006) stated that KM can effectively solve environmental issues. They found that a large quantity of data and information collected from EM projects can be systemized and organized into a KM system and can be used to solve environmental problems. EKM combines tacit knowledge from employees' experience and explicit knowledge from environmental tasks in order to improve teamwork efficiency and solve environmental problems. This can not only reduce pollutant emissions from production processes, but also enhance the precontrol and prevention of environmental pollution.

The difference between EKM and the environmental management information system (EMIS)

Environmental management information systems (EMIS) is an important component of environmental management that can assist both environmental and non environmental managers who fulfill their daily tasks. EMISs have been broadly defined as computer based technologies that support environmental management systems. However, Finster et al. (2001) define environmental knowledge management system as the consistent of the tools, mechanisms, processes, structures, people, policies, strategies, data and information that enable the creation, capture, accumulation, storage, retrieval, use and transfer of knowledge that improve an organization's overall impact on the environment. Therefore, EMIS is one specific part of EKM and could not represent whole of it. 


\section{Environmental knowledge circulation process (EKCP)}

Lee et al. (2005) measured knowledge management performance using the KCP which has five components: Knowledge creation, knowledge accumulation, knowledge sharing, knowledge utilization and knowledge internalization. Based upon KCP theory, this study will also evaluate the environmental performance of China Steel Corporation (CSC) via the EKCP which also has five components: Environmental knowledge creation (EKC), Environmental knowledge accumulation (EKA), Environmental knowledge sharing (EKS), Environmental knowledge utilization (EKU) and Environmental knowledge internalization (EKI).

Enterprises adopt the EKCP to convert external environmental knowledge into internal enterprise values with regards to environmental responsibility and sustainable development. In order to transform environmental issues into enterprise values and culture (Milliman and Clair, 1995), companies should develop a training strategy designed to motivate and improve employees environmental knowledge and awareness (Shrivastava, 1995; Getzner, 1999). Under increasing pressure from the trend of green innovation, enterprises can only remain competitive through the use of environmental knowledge management to enhance their profit and ensure their international competitiveness in the field of sustainable development.

\section{The components of the EKCP}

The EKCP is composed of continuous environmental knowledge activities distributed among EKC, EKA, EKS, EKU and EKI. Knowledge creation (KC) is further an understanding of the need to develop newer technologies and systems in order to enhance creativity and competitiveness (Quinn et al., 1996). Nonaka et al. (1994) indicated that there are four modes of knowledge conversion:

- Socialization (from tacit knowledge to tacit knowledge).

- Externalization (from tacit knowledge to explicit knowledge).

- Combination (from explicit knowledge to explicit knowledge).

- Internalization (from explicit knowledge to tacit knowledge).

The same concept is applied for KC with the transition mechanism, the tacit knowledge and explicit knowledge of EKC expanding in both quality and quantity throughout the above conversion processes.
The two essential components of EKA are experience and experimentation. From a resource based perspective, technological knowledge, skills and employees' experience are valuable assets that are accumulated over time in an enterprise and are even embedded in the organizational culture. Dierickx and Cool (1989) indicated that an organization's strategic asset stocks accumulates integrated resources over a period of time; however, a stock of knowledge usually resides in a particular person in the organization (Hedlund and Nonaka, 1993) and hence, EKA requires continuing efforts to acquire employees' experiences and the considerable allocation of organizational resources. Enterprises engage in environmental creation and $\mathrm{R}$ and $\mathrm{D}$ activities by EKA and increase their market competitiveness and advantage.

EKS is a kind of knowledge transaction between individuals and groups. Andersen and APQC, (1996) proposed the following Eq:

\section{$\mathrm{KM}: \mathrm{K}=(\mathrm{I}+\mathrm{P})^{\mathrm{s}}$}

EKI is the process of learning by converting explicit knowledge into tacit knowledge (Nonaka et al., 1994). Employees can access the environmental information and knowledge needed to complete tasks through a series of environmental training sessions and exercises.

The EKCP is a never ending process that continuously improves ensuring the obtaining of competitive advantage by creating, accumulating, sharing, utilizing and internalizing EM. Moreover, the production of cleaner products may enable companies to be continuously improved by identifying ways to maximize profits through creating and improving eco friendly productsm, reducing waste and pollution and increasing invisible corporate assets-an awareness and sense of environmental protection and eco-efficiency.

\section{MATERIALS AND METHODS}

The study is based on semistructured interviews carried out in 2007 with managers and engineers of China Steel Corporation (Tables 1 and 2) and information collected from the internet, thematic papers, case studies and CSC environmental reports.

The objectives of this research are:

- The implementation of EKCP in CSC.

- The transition of environmental knowledge in CSC 
(from the knowledge spiral theory viewpoint).

- Discussion of whether environmental knowledge management is able to effectively improve the performance of environmental management in CSC.

The authors are interested in how the EKM system works and why implementation is so successful in CSC.

This study will evaluate the environmental performance of CSC using the EKCP as described by Lee et al. (2005). The evaluation components are as follows: EKC; EKA; EKS; EKU and EKI which include the organization capacity to internalize task related to environmental knowledge, the environmental education opportunities and the level of organizational learning (Lee et al., 2005). The concept of this paper is to study whether the performance of EKM will improve and whether environmental targets will be achieved when the EKCP is effectively improved.

\section{Company background}

China Steel Corporation established in 1971 was the first integrated steel mill in Taiwan. After privatization in 1955, CSC concentrated on developing its steel business, as well as expanding its business into the CSC Group which operated and invested in diversified business areas. With maximally efficient resource integration among the subsidiaries and affiliates and an output of $10.7 \mathrm{~m} \mathrm{mt}$ of crude steel of CSC had become the world's twenty fifth largest steel producing company by 2006 (IISI, 2007).

To enhance their international competitive advantage, CSC set up a KM Committee in 2003 which was responsible for implementing KM in order to pass down the accumulated experience, technology and expertise of over $30 \mathrm{y}$ of operation. This is not only a corporate asset for future development and forward innovation, but also the best approach to sustainable development. According to Tony Chao, the manager of the Manpower Development Section, HR development of CSC indicates that employees' experiences are the most valuable company asset of CSC (n.d.). CSC invested capital in an E-learning program and combined this program with KM systematically transforming accumulated skills into a

Table 1: Details of interviews conducted on 2007/08/30

\begin{tabular}{ll}
\hline Name & Position and Department \\
\hline K. C. Liu & General manager, Environmental \\
& Protection Department \\
I. Y. Chen & Environmental Planning Section, \\
& Environmental Protection Department \\
\hline
\end{tabular}

Table 2: Details of interviews conducted on 2007/05/02

\begin{tabular}{ll}
\hline Name & Position and Department \\
\hline W. S. Tsai & $\begin{array}{l}\text { President of the Labor Union of China } \\
\text { Steel Corporation } \\
\text { T. Chao }\end{array}$ \\
& $\begin{array}{l}\text { Manager of the Manpower Development } \\
\text { Section, Human Resource Department. } \\
\text { Manager of the Employee Relations }\end{array}$ \\
C. P. Chang & Section, Human Resource Department. \\
& Engineer in the Labor Safety and Health \\
C. F. Lee & Section, Industrial Safety and \\
& Environmental Protection Department. \\
& Engineer in the Labor Safety and Health \\
C. L. Wu & Section, Industrial Safety and \\
& Environmental Protection Department. \\
\hline
\end{tabular}

digital system. Overcoming the limitations of location, time and budget, E-learning provides an organized and systematic KM system for all staff levels in CSC.

In addition to the development of the KM system, CSC has also demonstrated outstanding achievement in environmental management. Over the past two decades, CSC has contributed significantly to environmental protection initiatives; it integrated environmental protection activities and functions into the environmental management system (EMS) and obtained ISO14001 certification in 1997. Moreover, a multi-examination system was successfully developed into a total quality standard control and management system (TP00) which combines the benefits of a Quality Management System (ISO9001), EMS (ISO14001) and occupation health and safety management (OHSAS18001). All levels of staff in CSC are able to search and analyze all kinds of information and data more efficiently through the TP00 system. Furthermore, an EM meeting is held every six months and EM review is held every year by the EM Committee to ensure that the EMS is working effectively and appropriately (Industrial Safety and Hygiene News, 2005). Hence, CSC has received different types of awards from the government for industrial safety, hygiene and environmental protection since 1999.

\section{Steel production flow chart and environmental problems}

The environmental problems in steel production processes are complicated; therefore, the solutions are also complicated. Despite the complexities, it is possible to highlight the key emissions problems, including air pollution, water pollution and solid waste. Air pollution presents the main problems due to $\mathrm{CO}_{2}$, $\mathrm{SOx}$, NOx and particulate emissions. Gas scrubbing water, the water used in the rolling mills which can be of high oil content, 
electrolytic cleaning water, the water used for cooling, and the rust removal and lubrication processes are the main causes of the water pollution problems. Volumes of slag and the other by-products emanate from the production processes causing solid waste.

From the steel production flow chart (Fig. 1), the input sources of materials and resources and the output results of remnants and waste can be clearly identified. To solve these problems, CSC combines its accumulated production experience and EMS to continuously develop new technologies to reduce pollution during the production processes which is an example of the performance of EKM in CSC (Kuo-Chung Liu, general manager of the Environmental Protection Department, Production Division of CSC). In addition, CSC has implemented an environmentally-friendly production strategy and has invested more than nine hundred thousand USD on various environmental equipments in order to improve environmental quality through pollution prevention and waste reduction (Industrial Safety and Hygiene News, 2005).

\section{Environmental knowledge management in CSC}

What has CSC done to promote environmental protection?

In order to show the special emphasis and the business responsibility that CSC places on environmental protection, the environmental Protection Department (EPD), a new and independent department, was separated out from the Industry Safety and Environmental Protection Department in 2007. It is a professional department strongly supported by its high-level manager who is responsible for EKM and environmental issues. The change of the original organizational structure gives the EPD more power in resource integration and energy saving; it also increases the awareness of the EKCP in CSC.

\section{Environmental knowledge creation}

The EKM system is a complete and user friendly information system containing vast amounts of environmental knowledge and employees can search for related information and E-learning courses on the CSC internal database. The official environmental website related to environmental policies and foreign environmental information can also be searched through the CSC website and intranet. Outside the EKM system, entry-level engineers can also learn directly from senior engineers gaining environmental knowledge and experience (tacit knowledge) that can not be obtained by a search of the network. CSC also offers staff the opportunity to investigate new environmental protection knowledge and technology abroad.

Under the EKM system, predecessors usually give different challenges to their subordinates according to their ability and job attributes, the task specialty and complexity. Environmental engineers who are in charge of environmental tasks in different positions need a full understanding of the core environmental

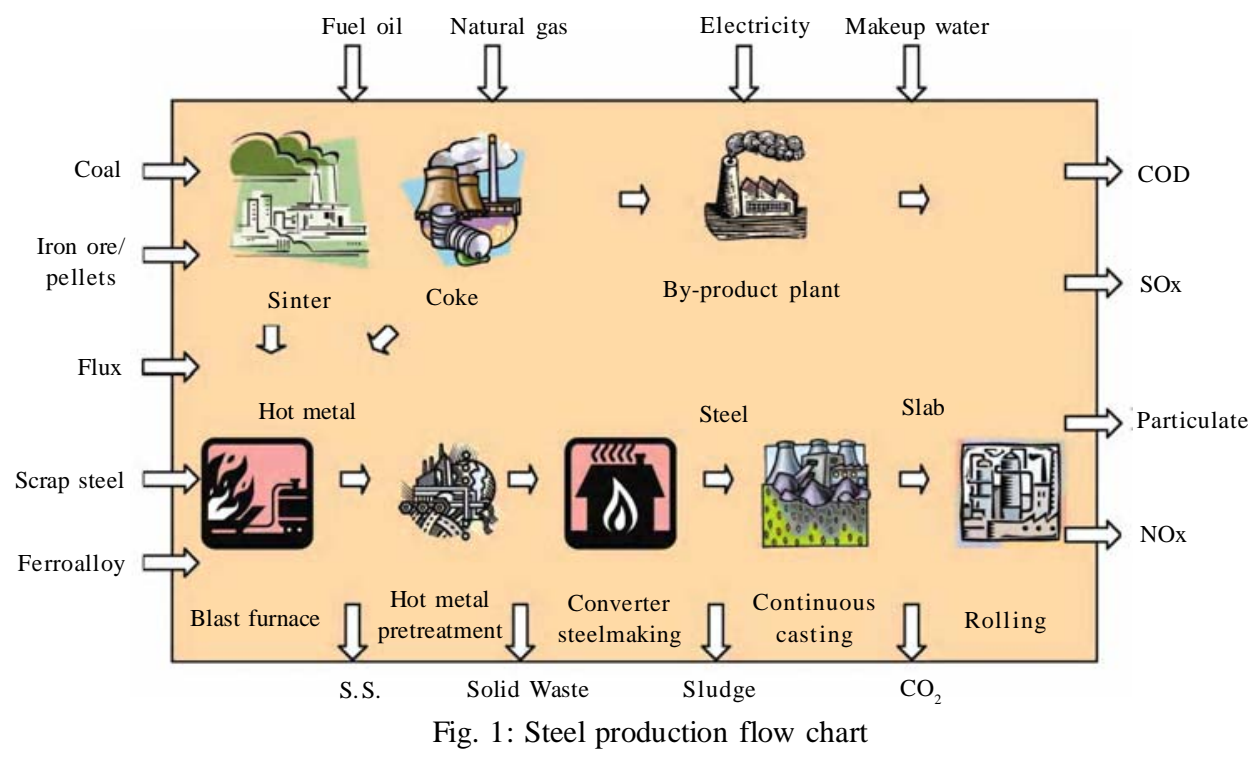


knowledge.

For example, engineers who are responsible for air pollution prevention must:

- Read the air pollution prevention policy;

- Undergo capability building and training programs for one month;

- Obtain related certification and become a professional in air pollution prevention management;

- Fully understanding of the concept of EM and apply it to air pollution prevention and control.

The EPD usually convenes brainstorming meetings to obtain useful environmental information, knowledge and suggestions. For instance, the EPD can communicate directly with the different departments, subsidiaries and affiliates of CSC during the weekly meeting to obtain information valuable for decisionmaking and the EM strategy. Due to this continuous brainstorming, engineers in the EPD are able to take up new challenges upon new environmental knowledge creation in order to create new technologies to reduce pollution and apply them to new tasks.

Environmental engineers will also search for suggestions and solutions through communities when they encounter thorny environmental problems. Therefore, professional environmental knowledge can be circulated freely through the systematic knowledge communities and the E-learning systems that were built up by the professional senior engineers.

\section{Environmental knowledge accumulation}

Wu, Engineer in the Labor Safety and Health Section, Industry Safety and Environmental Protection Department, usually searches for the necessary information or experts experience from various databases, communities and environmental knowledge bases while facing a difficult problem or a case similar to one that has occurred before. The environmental knowledge system of CSC is being continuously improved moving towards full computerization and a paperless system.

Moreover, Wu uses the safety auditing system as an example to explain how the necessary information and knowledge are searched through the environmentrelated databases to reach the environmental goals. According to WU, CSC usually makes routine checks and audits and then uploads the final results on the internal information system. This forms the training material for future use creating knowledge and increasing the benefits of knowledge management. For environmental protection and true environmental benefits, CSC observes environmental policies and continually strives to make the factory greener and improve the ecological environment and environmental quality. Environmental knowledge will be accumulated by learning stored in the environmental manual and shared via the intranet after completion of the pollution prevention projects or EM projects. Moreover, tacit knowledge will also be transformed into explicit knowledge and stored as electronic files or in the manual such as the transformation of presentations into media files or presentation articles. In the accumulation of environmental knowledge and environmental education, CSC conducts environmental training and provides abundant information on the courses which employees can also download from the internet.

\section{Environmental knowledge sharing}

According to the attributes and features of environmental knowledge and information, knowledge sharing can be classified as:

- Latest information: CSC usually shares the latest information in meetings and in conferences;

- Special information for a specific person/position: Different environmental information and knowledge is passed on via documents or Emails to a specific person or particular positions;

- General information: General information is posted on the electronic bulletin board to share with all employees of CSC.

CSC shares environmental knowledge and information with external and internal teams through the regular meetings and conferences which encourages employees to be more interested in the environmental work of the company. With regards to external teams, CSC usually exchanges environmental opinions and new technologies with the CPC Corporation, Taiwan Power Company and the Formosa Plastics Group as for internal teams, environmental protection and pollution control information is widely circulated through conferences in order to improve environmental knowledge sharing and achieve the organization environmental goals. Wu, President of the Labor Union of CSC, emphasizes that there is no secret in the skills and techniques of environmental protection and industrial safety issues. Moreover, a successful 
and responsible enterprise should be concerned about its social and environmental responsibility, contribute to environmental infrastructure development, integrate resources and take action towards attaining global sustainability. CSC has developed metadata, a file system defined as the data about the data in the knowledge database system. It includes that description of content, file size, author, publication date and physical location is an effective data management system that varies with the type of data, the context of use and the content of files. Using metadata, it is easier to increase the system speed, enrich the searchable resources and share environmental knowledge. Of course, document security has been seriously considered and ensured during knowledge sharing.

\section{Environmental knowledge utilization}

An electronic exchange system is used in EKM. A systematic EKM system enables environmental tasks to be implemented smoothly. In addition, participation in environmental activities leads to better environmental performance relying on the utilization of environmental knowledge in CSC. According to Wu, CSC has a high quality environmental education program and has taken advantage of the existing knowledge creation and sharing in the organizational culture to improve the EKM system. CSC provides incentives such as product awards, individual awards and innovation awards for the employees who have demonstrated outstanding performance in EKM, knowledge conservation and environmental protection.

\section{Environmental knowledge internalization}

CSC has compiled handbooks and manuals with a view to improv employees occupational knowledge. This enables the employees to better understand their job and the work required skills. In addition, some departments download the environmental course information from the internet and some also use the environment related courses to improve employees' capability and develop their sense of environmental responsibility.

Under Environmental Protection Department, the environmental resource and information standard system is set up to assist employees to implement environmental task. The professional information system is reviewed and updated continuously which allows employees to search the environmental information and accumulate knowledge through the system that can be used to complete new tasks. Through this process, employees can internalize explicit environmental knowledge into their tacit knowledge and gain environmental awareness. The use of an environmental information system speeds up the sharing and internalization of environmental knowledge.

\section{RESULTS AND DISCUSSION}

Based on their existing environmental knowledge experience, CSC continuously creates new environmental knowledge through brainstorming sessions and meetings. It also implements master and apprentice schemes and reward systems to inspire employees to pass down their accumulated knowledge and experience. According to the attributes of the knowledge and the level of the employees, the sharing of environmental knowledge enables employees to have a greater understanding of the environmental information which means that the environmental knowledge is passed down to the right person at the right time making the EKCP more active and effective. The mechanism of the conversion activity enables the environmental knowledge to be internalized into the employee personal values and improve the awareness of environmental protection issues. Environmental knowledge is also internalized knowledge improving employees personal potential capability of creating new environmental knowledge, technologies and skills. Circulation activities maximize the value of environmental knowledge which is also the purpose of environmental knowledge management. According to IISI (2006), CSC had become the world's seventeenth largest (and Asia's eighth-largest) steel making group by 2000. In addition, CSC was listed in A-list on Forbes 2003 as one of the 400 best large companies of the world. Moreover, CSC was designated by IISI as twenty fifth out of eighty top steel producing companies in 2006 (IISI, 2006) which demonstrates the performance and implementation of environmental knowledge management in CSC.

From the interviews conducted in this study, it is clear that CSC uses environmental knowledge activities to its advantage and continuously creates, accumulates, shares, utilizes and internalizes environmental knowledge enabling EKM to mesh with CSC's ethos, mission and vision (Fig. 2). External stresses such as environmental policies, WEEE, RoHS, 
awareness of the environment, green innovation and social responsibility all speed up the improvement of EKM in CSC. Moreover, in consistently improving with EKM activities, environmental knowledge is internalized CSC business spirit, organizational values, competitive advantage and organizational culture which drives CSC to use its environmental knowledge and ideas in product design and the production process. Therefore, CSC has built up a complete and high quality EM system through the EKCP providing a good example for other enterprises to follow.

\section{Environmental performance}

According to the environmental load of Chinese Steel Corporation, this report will be referred to the environmental load generated in 2004, including input of resources and energy, as well as gas, liquid and solid output. This report indicates the current status along with improvement measures taken in the past years.

Indicators are calculated based on each ton of steel products, including:

- Unit consumption of energy and discharge of $\mathrm{CO}_{2}$ gas.

- Unit discharge of $\mathrm{NO}_{\mathrm{x}}, \mathrm{SO}_{\mathrm{x}}$ and particulates from waste gases.

- Unit consumption of water and unit discharge of chemical oxygen demand and suspended solids (SS) in effluent.

- Generation of the by-products process and the recycled or disposed percentages.

Therefore, environmental performance really can be improved through the performance of EKM.

In response to environmental regulations and increasing of environmental awareness, CSC implemented environmental technology and managed solutions to reduce emissions and natural resource demands and control waste. For instance, water treatment has been a major concern; it includes physical, chemical and biological treatment to remove or change the composition of coke effluent before releasing or recycling. The water recirculation system ensures water efficiency and enables reuse of water to reduce production costs. CSC is still searching for new environmental knowledge to reduce the environmental pollution, energy demand and manufacturing cost via the newest recycling technologies.

\section{Water pollution control and water consumption}

CSC method of water pollution control and consumption is an in-plant process that reduces and eliminates the generation of pollutants and waste to reduce risk to human health and the environment. CSC has taken effective measures to reduce the environmental risk and preserve natural resources through wastewater treatment systems, the secondary water reuse system and the rain recycling system.

CSC plantwide water recycling and reuse plan maximize the efficiency of water consumption and the recycling of $97.6 \%$ of water is normally achievable. A significant development of CSC in the area of water consumption is the reduction and prevention of water pollution through water recycling and saving.

Fig. 3 shows the trend of chemical oxygen demand (COD) and suspended solids over the past seven years for CSC. CSC waste water treatment system has reduced the content of COD from $71 \mathrm{ppm}$ in 2000 to $41 \mathrm{ppm}$ in 2006 and that of SS from $9.7 \mathrm{ppm}$ in 2000 to $4.4 \mathrm{ppm}$ in 2006. This not only reduces the total operating costs, but also achieves CSC environmental objectives.

\section{Air emission control}

The Environmental Surveillance Center of CSC established in 1995 continuously monitors, analyzes and controls the emissions and effluents from the manufacturing process. Three monitoring systems are used in pollution prevention and EM: periphery air monitors and displays boards, continuous monitors for off gases and year round visual monitors. With the aim of increasing environmental protection, the high performance of the air control system is shown in Fig. 4; from the relative index, the emissions of particulates, SOx and NOx in 2006 were $91 \%$, $79 \%$ and $67 \%$, respectively which are much lower than the same values measured in 1992 (Payne, 2001).

The important outcomes of the resource reducing project and the energy saving program in CSC are shown in Table 3. CSC reduces greenhouse gases through internal and external improvement programs such as waste heat recovery, the application of energy-saving in the producing process, improving the yield rate, regional energy integration, the zero-waste project, etc.

\section{Energy consumption}

As the steel making industry is an energy-intensive industry and this energy constitutes up to $20 \%$ of the 


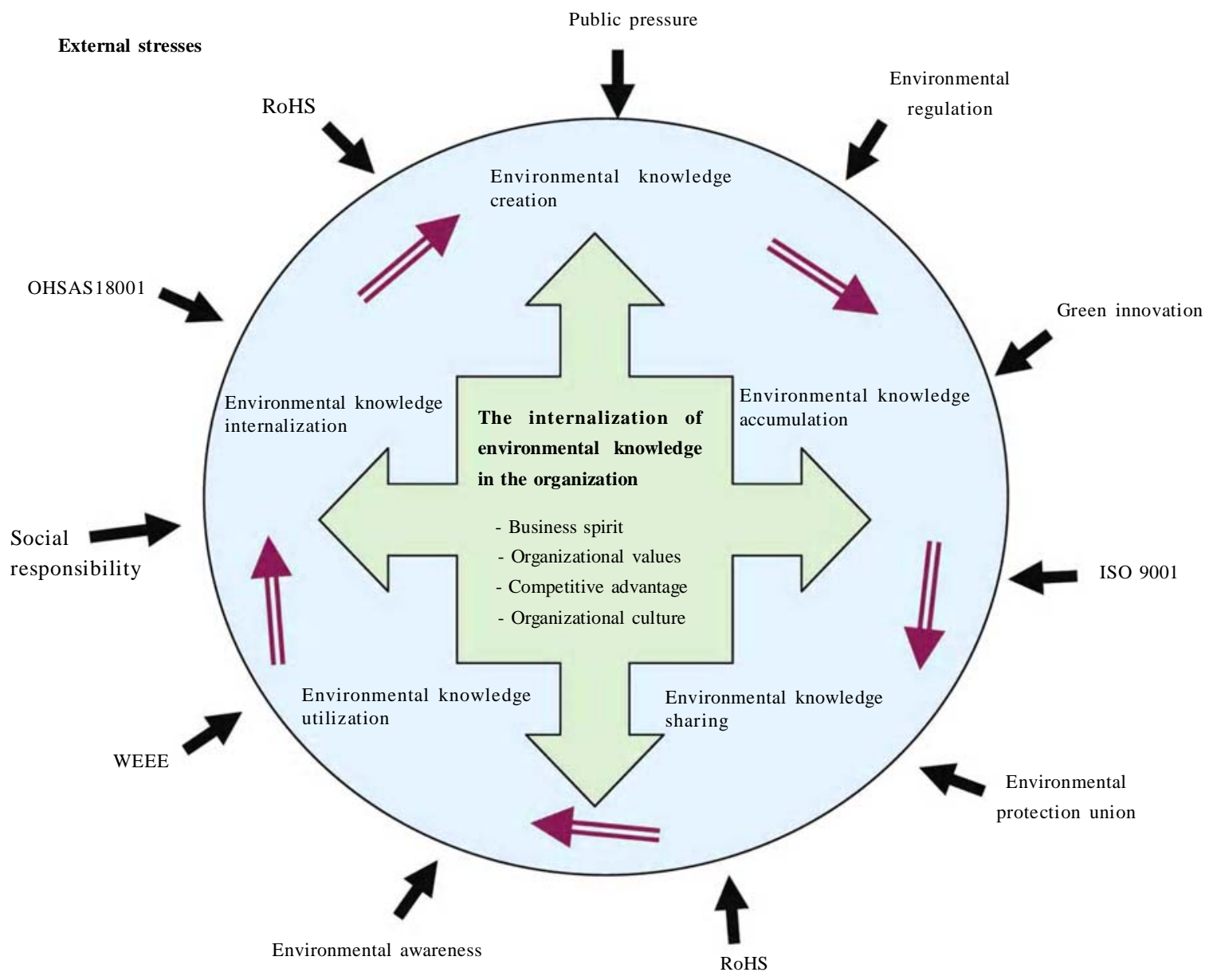

Fig. 2: The circulation of environmental knowledge in CSC

cost of steel making, energy consumption has become a major factor affecting global competitiveness. As shown in Fig. 5, the major input of energy consumption is coking coal (73.8 \%); others are BF injection coal (16.1\%), electricity (5.1\%), steaming coal (3.8\%), etc. Moreover, considering the various changes in the international market and the shortage of natural resources, CSC felt it necessary to refocus on energy efficiency and reducing the consumption rate. Hence, an advanced steel making technology was created and is used in CSC. Compared with the energy consumption in 1979 , the relative index shows that it has been reduced by $20 \%$ in 2006 as previously reported by CSC (Fig. 6).

Reduction of process residues and recycling toward zero waste

CSC zero waste philosophy in environmental matters leads to the recycling, reuse, conservation and by-products production of useful mineral products, materials and resources. The benefits of a zero waste policy are that it reduces operation costs, increases profit and complies with environmental regulations. CSC continuously creates new technology to reduce waste or transfer it into useful resources through continuous improvement in the manufacturing process, consistently moving towards a zero waste system. With the improvements in technology and investment in the $\mathrm{R}$ and D Department over the past two decades, CSC has accomplished its missions and goals gradually.

Its performance in reducing residues and recycling will be shown in the following tables and figures.

Fig. 7 presents the percentage of sludge recycled at CSC. The recycling of sludge has improved over the years and the goal of one hundred percent of recycling was achieved in 2000. Table 5 shows the internal and 


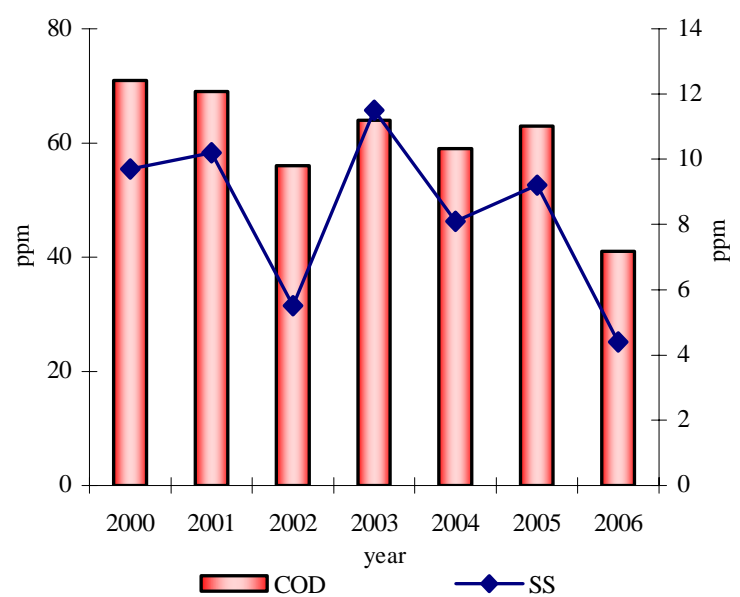

Fig. 3: COD and SS of the effluent (Payne, 2001)
Table 3: The performance of $\mathrm{CO}_{2}$-reducing projects (Payne, 2001)

\begin{tabular}{lcl}
\hline Project & \multicolumn{2}{c}{$\begin{array}{c}\text { Contribution } \\
\left(1,000 \text { ton- } \mathrm{CO}_{2} / \text { year }\right)\end{array}$} \\
\hline $\begin{array}{l}\text { Waste heat recovery } \\
\text { Project }\end{array}$ & 1,300 & $\begin{array}{l}\text { Total energy saving from } \\
1997 \text { to } 2006\end{array}$ \\
$\begin{array}{l}2010 \text { energy-saving } \\
\text { Project }\end{array}$ & 160 & Total energy saving in 2006 \\
$\begin{array}{l}\text { Eco-industrial park* } \\
\begin{array}{l}\text { Water-quenched slag } \\
\text { replacing the use of } \\
\text { Concrete }\end{array}\end{array}$ & 210 & Ton- $\mathrm{CO}_{2} / \mathrm{KLOE}$ \\
\end{tabular}

* Eco-industrial park means CSC sold energy which it did not need and gases such as $\mathrm{N}_{2}, \mathrm{O}_{2}$, coal breeze and steam to increase income and reduce pollution.

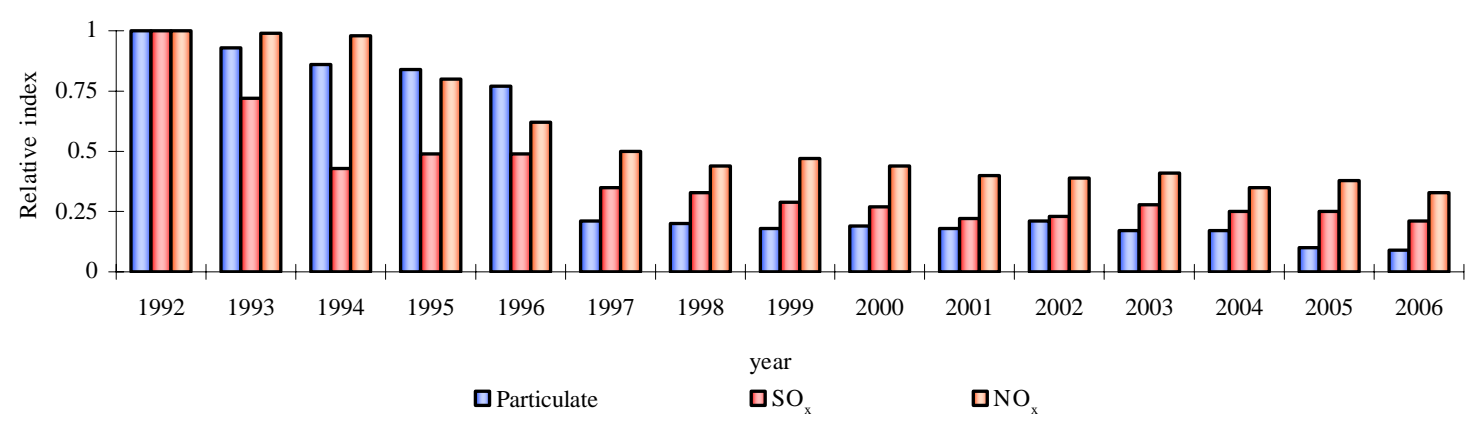

Fig. 4: Air pollution per ton of steel production (relative index) (Payne, 2001)

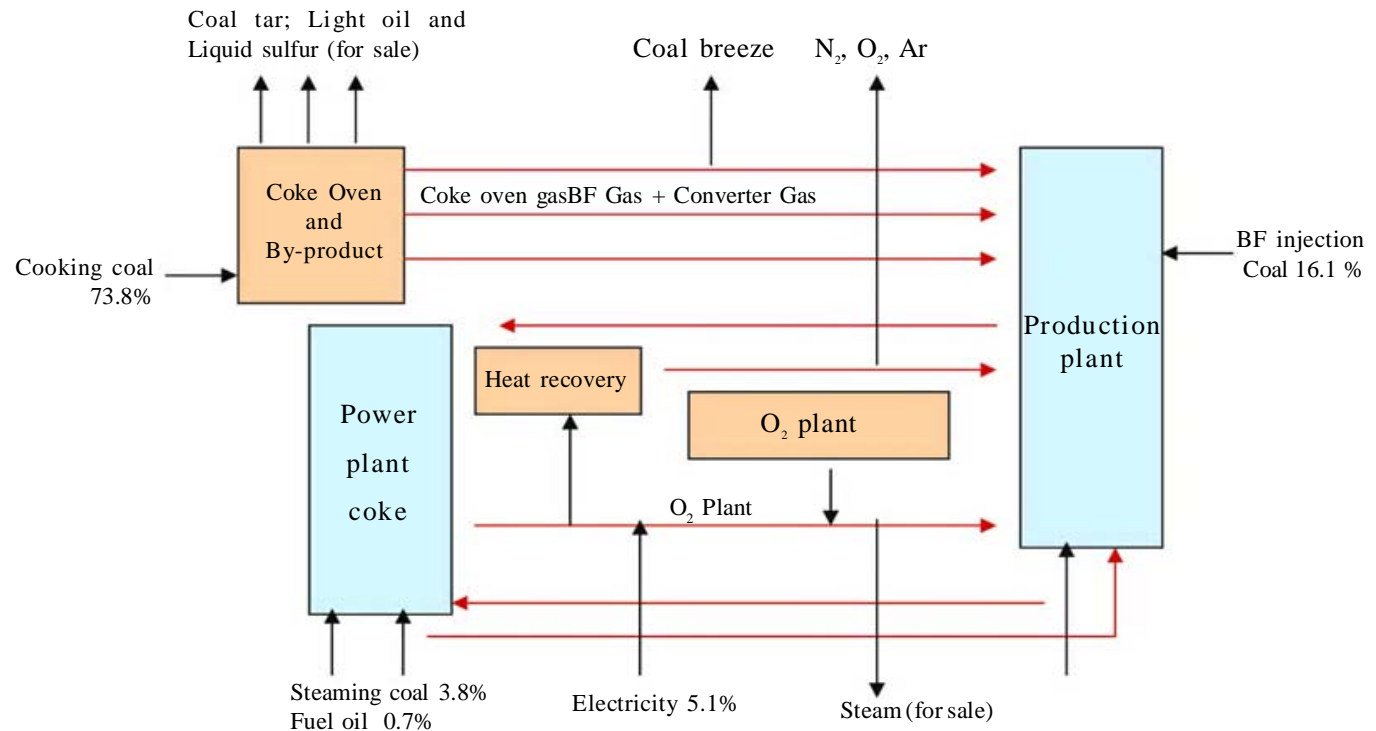

Fig. 5: Major inputs and outputs and flowchart (dry basis, for each ton of steel produced) (Industrial safety and hygiene news, 2005) 
external recycling and the disposal from the steel making process in 2006. All residues are $100 \%$ recycled of which $21.2 \%$ are for internal use and $78.8 \%$ are sold for external use.

\section{Financial performance}

The strategy of CSC eco-industrial park is not only to maximize energy efficiency and financial performance, but also reduce the environmental burden. Steam, $\mathrm{N}_{2}, \mathrm{O}_{2}$ and Ar are generated during the steel making process and are sold to external plants such as China Petrochemical Development Corporation at KHH, Tang Eng Stainless Steel Plant, China Steel Chemical Corporation, etc. The financial gain from sold energy is shown in Fig. 8 from which it can be seen that profit has increased from 4.12 million USD in 1994 to 33.66 million USD in 2006.

In addition to the increase in revenue gained from the energy sold to nearby plants, CSC also reduces its costs by increasing the pulverized coal injection (PCI) rate and reducing the fuel rate which can save 6.59 million USD each year. Also, the rain recycling system can collect 150 thousand tons of water which can save around 66 thousand USD each year; the waste heat recovery system can save 72.46 million USD each year and the acid regeneration plant (ARP) will reduce the cost of acid purchasing by 3.95 million USD. Hence, to eliminate energy waste and increase financial performance, CSC also continuously improves its management strategies and technology in order to improve the overall energy efficiency.

Application of EKM in strategy planning and performance improvement

The change in the organizational structure of CSC has enabled the EPD to concentrate on strategy and planning related to environmental issues, integration of natural resources and prevention of pollution in production. Strong support from executives drives the success of CSC in EKM and environmental performance. In addition, managers usually apply the newest techniques to reduce pollution due to the environmental concerns and social responsibility. The organizational change of CSC was also significant in establishing dynamic strategy planning, executing EKM and achieving continuous environmental

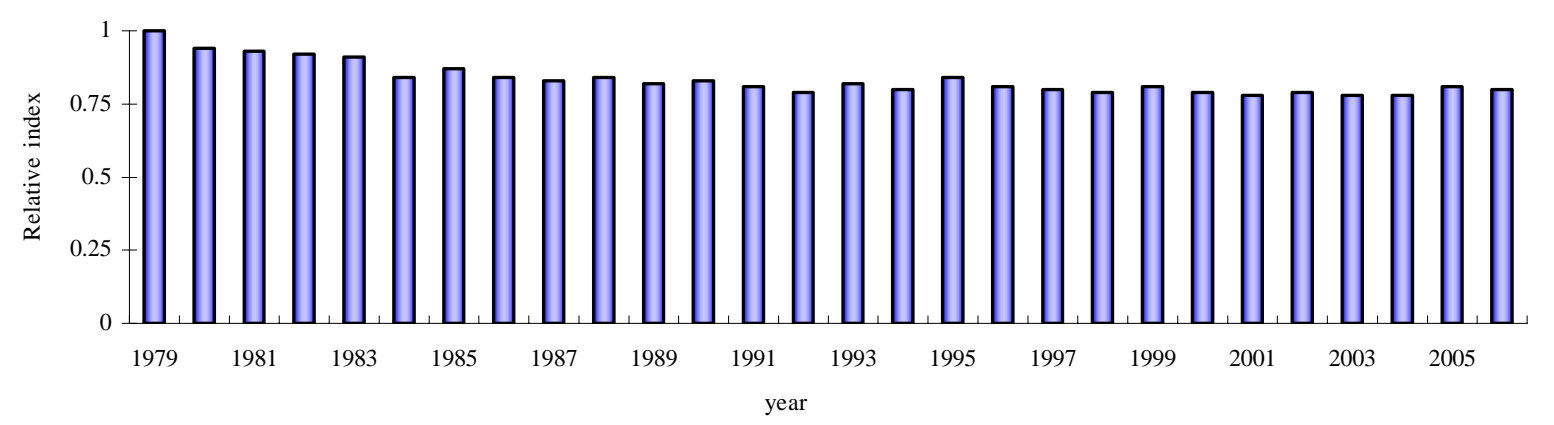

Fig. 6: Energy consumption of CSC, 1979-2006 (relative index) (Payne, 2001)

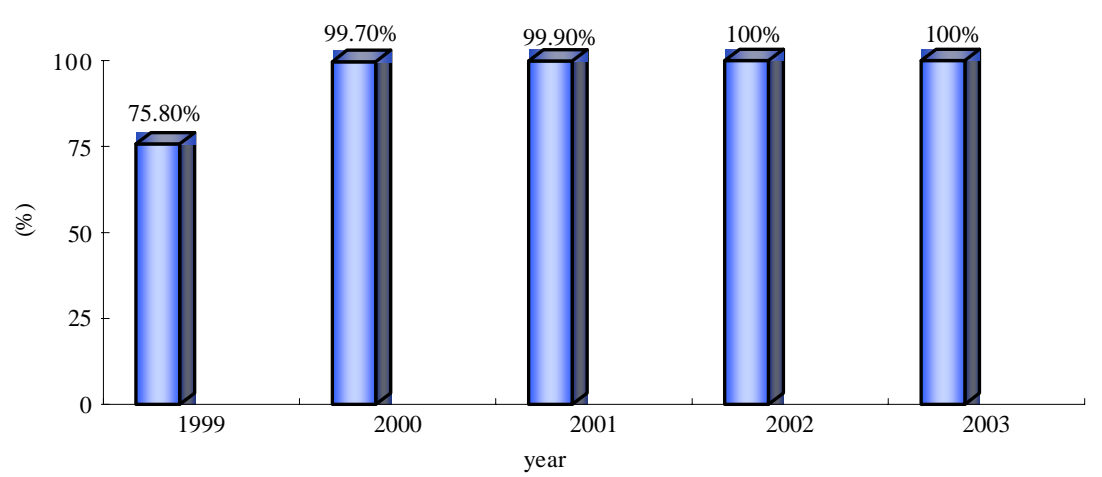

Fig. 7: Percent of sludge recycled at China Steel Corporation since 1999 (IISI, 2006) 
Int. J. Environ. Sci. Tech., 6 (1), 35-50, Winter 2009

Table 4: By-products of process residues in 2004 (Payne, 2001)

\begin{tabular}{|c|c|c|c|}
\hline Type of residue & Description & $\begin{array}{c}\text { Generation } \\
(10,000 \text { tons })\end{array}$ & $\begin{array}{c}\text { \% of total } \\
\text { residues }\end{array}$ \\
\hline BF slag & By-products of BF after smelting or raw materials & 303.9 & 49.0 \\
\hline BOF slag & By-products of the basic oxygen furnace (BOF) after refining of steel & 128.2 & 20.6 \\
\hline De-S slag & By-products of the hot metal desulfurizing process & 36.8 & 5.9 \\
\hline Dust & Particulates collected from de-dusting system & 34.1 & 5.5 \\
\hline Sludge & Solid cakes or mud from wastewater treatment after condensing and dehydrating & 44.8 & 7.2 \\
\hline Mill scale & Rust of steel products or semi-products & 29.4 & 4.7 \\
\hline Spent refractory & Used refractory from high temperature process & 4.0 & 0.6 \\
\hline Civil refractory & Residual soil, concrete, etc. & 19.8 & 3.2 \\
\hline Limestone cake & Filter cake from limestone washing water & 5.0 & 0.8 \\
\hline Other & Waste oil, waste packaging materials, refuse, etc. & 15.5 & 2.5 \\
\hline Total & & 621.5 & 100 \\
\hline
\end{tabular}

Table 5: Internal and external recycling and the disposal from the steel making process (Payne, 2001)

\begin{tabular}{|c|c|c|c|c|}
\hline Type of residue & $\begin{array}{l}\text { Recycled } \\
\text { internally } \\
(\%)\end{array}$ & $\begin{array}{l}\text { Recycled } \\
\text { externally } \\
(\%)\end{array}$ & Applications & $\begin{array}{l}\text { Disposal } \\
\text { (solid or landfill) }\end{array}$ \\
\hline BF slag & 4.5 & 95.5 & $\begin{array}{l}\text { Water-quenched to produce slag powder or air-cooled to } \\
\text { be used as aggregates }\end{array}$ & 0 \\
\hline BOF slag & 9.8 & 90.2 & $\begin{array}{l}\text { Blast furnace flux, slag pot base material, land reform, } \\
\text { temporary road, backfill materials for the South Star } \\
\text { Project }\end{array}$ & 0 \\
\hline De-S slag & 0 & 100 & $\begin{array}{l}\text { Land reform, temporary road, soil conditioning and } \\
\text { cement making }\end{array}$ & 0 \\
\hline Dust & 98.4 & 1.6 & Mixture of fly ash and sludge as cement making material & 0 \\
\hline Sludge & 68 & 32 & Cement making material & 0 \\
\hline Mill scale & 93.8 & 6.2 & Sales & 0 \\
\hline Spent refractory & 90.9 & 9.1 & $\begin{array}{l}\text { For steel and refractory making, or for land reform after } \\
\text { metal recovery }\end{array}$ & 0 \\
\hline Civil refractory & 0 & 100 & Landfill at the South Star Project & 0 \\
\hline Limestone cake & 0 & 100 & Admixture of civil material & 0 \\
\hline Other & 63.3 & 36.7 & Reverse recycling, sales, etc. & 0 \\
\hline Total & 21.2 & 78.8 & & 0 \\
\hline
\end{tabular}

improvement through EKM activities. The implementation of CSC environmental protection strategy enables engineers to prevent problems and prepare possible solutions in advance. According to the manager of environmental protection, CSC used to invest in new mills without considering the environmental loading until problems began to appear. To avoid the same pollution problems, the EPD integrates all the related departments and production resources, including upstream, downstream, cross departments and the environmental management system, etc. to reduce the total environmental loading and pollution. The main concept is to implement pollution prevention and core process management strategies in advance instead of having to find a solution to the pollution problem. Using an iterative four step problem solving process, the PDCA (PlanDo-Check-Action), the EPD collects related production data and develops evaluation forms for pre-evaluation, in process-evaluation and post-evaluation during new plant construction. The EKM system enables the EPD to develop new technical knowledge through knowledge creation, estimate the results from the accumulated experience and utilize pollution prevention technologies in advance.

Another example is the system improvement project which helped the EPD to estimate the pollution results during the project planning stages. The system 


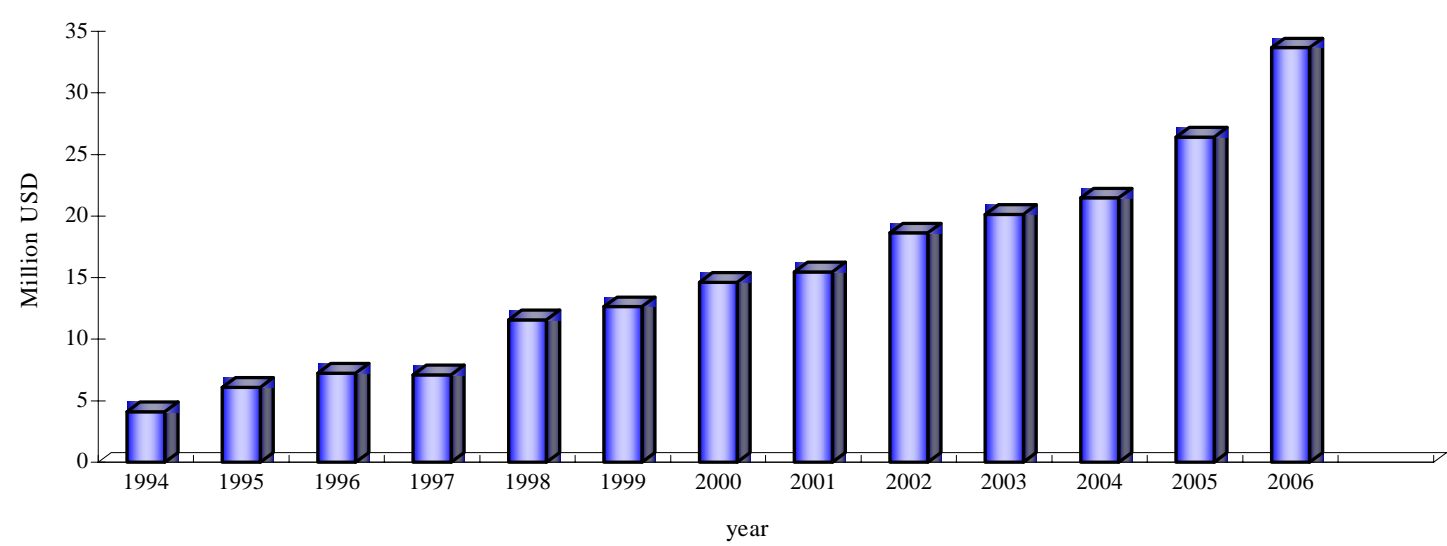

Fig. 8: Energy sold from 1994 to 2006 (million USD) (Payne, 2001)

improvement project integrated the EPD, Energy Department and R and D Department and focused on both comprehensive and objective pollution prevention in order to achieve the company's pollution reduction goals. Moreover, the basic aim of the system improvement project was to achieve user-friendliness, simplification and efficiency; it was well-accepted and effectively implemented by all departments because of its standard processes and simple design.

Through a combination of strategyplanning and EKM, EPD can calculate the environmental loading exactly according to the accumulated data and experience which helps to manage pollution prevention, green design, energy saving and resource integration. EPD calculates not only environmental loading in CSC, but also the secondary environmental loading upstream and downstream. Therefore, EKM is a continuous environmental activity involving the creation, accumulation, sharing, utilization and internalization of knowledge which helps CSC to take action before environmental accidents occurence, increase R and D investment, create green technology and develop green products; it also helps managers to make eco-efficient and strategy efficient decisions and identify the best investment projects in order to reach the goal of sustainable development.

\section{CONCLUSION}

From the perspective of the knowledge spiral theory (Nonaka and Takeuchi, 1996), it has been demonstrated that the conversion of EKM in CSC resultes in:

1- Socialization: Tacit knowledge is gained from accumulated experience;

2- Externalization: Accumulated experience and knowledge are converted into systematic explicit knowledge;
3- Combination: Opinions are exchanged between the knowledge community and community of practice, both internally and externally;

4- Internalization: The environmental knowledge is internalized into CSC company ethos and social responsibility.

CSC is one of the obvious organizational learning example which can develope "The Five Learning Cycle of Competent Organization”(Sanchez, 2001) because it has improved their environmental performance and has benefited greatly from EKM and the five learning circle such as in financial savings, value-added product design, energy savings and green competitiveness. It has improved its EKM through the EKCP: The creation, accumulation, sharing, utilization and internalization of environmental knowledge. The sharing of information is the foundation for creating and implementing a method of improving and developing new technology and designing environmentally friendly products. New technology creation also enables CSC to play a leading role in green product and steel making technology development. With continuous improvement of the EKCP, energy efficiency can often be achieved through integrated strategy planning. Installing water saving technology, introducing treatment techniques and using recirculating systems can lead to the reduction of water consumption. Moreover, the elimination of air emissions, water pollution and waste ensure the conservation of a better environment for future generations. Hence, CSC consistently enhances its international competitiveness and protects the quality of the environment which also helps the company to create a win-win situation corporate and environmental sustainable development. 


\section{ACKNOWLEDGEMENTS}

The authors would like to thank the China Steel Corporation for providing internal information. The authors especially wish to thank Kuo-Chung Liu, I-Yueh Chen, Wu Shun Tsai, Tony Chao, Chio-Po Chang, C. F. Lee and C. L. Wu for participating in the interviews and providing helpful assistance. The authors also especially wish to thank the financial support of Meiho Institute of Technology.

\section{REFERENCES}

Andersen, A.; APQC, (1996). The knowledge management assessment tool, external benchmarking version, The American productivity and quality center.

Bishop, P. L., (2000). Pollution prevention: Fundamentals and practice, McGraw-Hill, London, UK.

Boiral, O., (2002). Tacit knowledge and environment management. Long Range Plann., 35 (3), 291-317.

Chien, M. K.; Shih, L. H., (2007). An empirical study of the implementation of green supply chain management practices in the electrical and electronic industry and their relation to organizational performances., Int. J. Environ. Sci. Tech., 4 (3), 383-394.

Desouza, K. C.; Evaristo, J. R., (2003). Global knowledge management strategies., Eur. Manage. J., 21 (1), 62-67.

Dierickx, I.; Cool, K. (1989). Asset stock accumulation and sustainability of competitive advantage., Manage. Sci., 35 (12), 1504-1511.

Dourojeanni, A., (1993). Management procedures for sustainable development, applicable to municipalities, micro-regions and hydrographic basins. Economic commission for latin america and caribbean (CEPAL), 452.

Drucker, P., (1995). Managing in a time of great change, Penguin, New York.

Finster, M .; Eagan, P.; Hussey, D., (2001). Linking industrial ecology with business strategy: creating value for green product design., J. Ind. Ecol., 5 (3), 107-125

Forbes, (2003). The world's best big companies. Special Report. Available at: http://www.forbes.com/2003/04/09/ aland.html.

Frick, J.; Kaiser, F. G.; Wilson, M., (2004). Environmental knowledge and conservation behavior: Exploring prevalence and structure in a representative sample., Pers. Indiv. Differ., 37 (8), 1597-1613.

Fryxel, G.; Lo, C. W., (2003). The influence of environmental knowledge and values on managerial behaviours on behalf of the environment: An empirical examination of managers in China., J. Bus. Ethics, 46 (1), 45-69.

Getzner, M., (1999). Cleaner production, employment effect and socio-economic development., Int. J. Tech. Manage., 17 (5), 522-43.

Goodland, R., (1995). The concept of environmental sustainability., Ann. Rev. Ecol. Syst., 26, 1-24.

Hansen, M. T.; Nohria, N.; Tierney, T., (1999). What's your strategy for managing knowledge?, Harvard Bus. Rev., 77 (2), 106-116.

Hedlund, G.; Nonaka, I., (1993). Models of knowledge management in the west and Japan, in: Lorange, P.;
Chakravarthy, B.; Roos, J.; Van de Van, A., (Eds.) Implementing strategic processes: Change, learning, and CoOperation, London: Basil Blackwell, Ltd, 117-144.

Howells, J. (1996) Tacit knowledge, innovation and technology transfer., Tech. Anal. Strateg, 8 (2), 91-106.

Hsu, C. W.; Hu, A. H., (2008). Green supply chain management in the electronic industry., Int. J. Environ. Sci. Tech., 5 (2), 205-216.

IISI, (2006). Top steel producers, the international iron and steel institute, Available at: http://www.worldsteel.org/ ?action=storypages\&id=151.

IISI, (2007). World Steel in Figures, the international iron and steel institute, Available at: http://www.worldsteel.org/

Industrial Safety and Hygiene News, (2005). industrial safety and hygiene and environmental protection report china. Available at: http://www.highbeam.com/doc/1G1-79003633. html.

Inkpen, A. C., (1996). Creating knowledge through collaboration., Calif. Manage. Rev., 39 (1), 123-140.

?action=storypages \&id $=23$.

Johannessen, J.; Olsen, B., (2003). Knowledge management and sustainable competitive advantages: The impact of dynamic contextual Training., Int. J. Inform. Manage., 23 (4), 277-289.

Lee, K. C.; Lee, S.; Kang, I., (2005). KMPI: measuring knowledge management performance., Inform. Manage., 42 (8), 469-482.

Lorrain Smith, R., (1982). The nature of environmental management., J. Environ. Manage., 14 (3), 229-236.

Malhotra, Y., (1998). Knowledge management for the new world of business., J. Qual. Participate., 21 (4), 58-60.

Mangun, D., (2001). Product portfolio design for component reuse, remanufacturing and recycling., M. S. thesis in Civil and Environmental Engineering. University of Illinois, Urbana, IL, USA.

Milliman, J.; Clair, J., (1995). Environmental HRM best practices in the USA., Greener Manage. Int., 10, 34-48.

Nonaka, I., (1991). The knowledge-creating company., Harvard Bus. Rev., 69, 96-104.

Nonaka, I.; Byosiere, P.; Borucki, C. C.; Konno, N., (1994). Organizational knowledge creation theory: A first comprehensive test., Int. Bus. Rev., 3 (4), 337-351.

Nonaka, I.; Takeuchi. H.; Umemoto, K., (1996). A theory of organizational knowledge creation., Int. J. Tech. Manage., 11, (7-8), 833-845.

Nouri, J.; Karbassi, A. R.; Mirkia, S., (2008). Environmental management of coastal regions in the Caspian Sea. Int. J. Environ. Sci. Tech., 5 (1), 43-52.

O’Leary, D. E., (1998). Enterprise knowledge management., Computer, 31 (3), 54-61.

Payne, M., (2001). China steel corporation: An Asian major looks to regional Opportunities., Available at: http:// www.allbusiness.com/primary-metal-manufacturing/ironsteel-mills-ferroalloy/837732-1.html.

Petak, W. J., (1980). Environmental planning and management: the need for an integrative perspective., Environ. Manage., 4 (4), 287-295.

Prahalad, C.; Hamel, G., (1990). The core competency of the corporation., Harvard Bus. Rev., 68 (3), 79-91.

Quinn, J. B.; Anderson, P.; Finkelstein, S., (1996). Managing professional intellect: Making the most of the best., Harvard 
Bus. Rev., 74 (2), 71-80.

Sanchez, R., (2001). Product, process and knowledge architectures in organizational compentence, in: Sanchez, R. (Ed.), Oxford university press, New York, USA.

Sarvary, M., (1999). Knowledge management and competition in the consulting industry., Calif. Manage. Rev., 41 (2), 95-107.

Shrivastava, P., (1995). The role of corporations in achieving ecological sustainability., Acad. Manage. Rev., 20 (4), 936-60.

Swan, J.; Newell, S.; Robertson, M., (2000). Limits of ITdriven knowledge management initiatives for interactive innovation processes: Towards a community-based approach., Proceedings of the $33^{\text {rd. }}$ Hawaii International Conference on System Sciences.

Tatsuki, S.; Masahisa, N., (2006). Application of knowledge management to environmental management project: A case study for lake management. Lakes and reservoirs., Resour. Manage., 11 (2), 97-102.

Toffler, A., (1990). Power shift: Knowledge, wealth and violence at the edge of the $21^{\text {st. }}$ century., Bantam Books, New York, USA.

Wagner, M., (2005). How to reconcile environmental and economic performance to improve corporate sustainability: corporate environmental strategies in the European paper industry., J. Environ. Manage., 76 (2), 105-118.

WCED, (1987). Our common future: World commission on environment and development, Oxford University Press, USA.

Wernick, I. K., (2003). Environmental knowledge management., J. Ind. Ecol., 6 (2), 7-9.

\section{AUTHOR (S) BIOSKETCHES}

Po-Shin Huang, Lecturer, Meiho Institute of Technology, 23, Pingguang road, Neipu, Pingtung and Ph.D. research student in Resource Engineering, National Cheng Kung University, 1, Ta-Hsueh Road, 701 Tainan, Taiwan. Email: kevinhuang3145@yahoo.com.tw

Li-Hsing Shih, Ph.D., Professor, Department of Resources Engineering, National Cheng Kung University, 1, Ta-Hsueh Road, 701 Tainan, Taiwan. Email: Ihshih@mail.ncku.edu.tw

This article should be referenced as follows:
Po-Shin Huang; Li-Hsing Shih, (2008). Effective environmental management through environmental knowledge
management. Int. J. Environ. Sci. Tech., 6 (1), 35-50.

